\title{
A Perspectiva Sistêmica para a Clínica da Família ${ }^{1}$
}

\author{
Liana Fortunato Costa ${ }^{2}$ \\ Universidade de Brasília
}

\begin{abstract}
RESUMO - O presente texto tem por objetivo traçar uma breve trajetória teórica, conceitual, empírica e tecnológica do estudo da família na perspectiva sistêmica e apontar a consequente proposta de intervenções para a clínica da família. Apresentamos as diferentes Escolas de Terapia Familiar, desde aquelas fortemente influenciadas pela Cibernética até aquelas que assimilaram as contribuições do Construtivismo e do Construcionismo Social. A seguir, tecemos comentários sobre a pesquisa com família e os interesses dos pesquisadores da área em nosso país. Finalmente, apontamos nossa opinião sobre o direcionamento futuro da Terapia Familiar no Brasil.
\end{abstract}

Palavras chave: família; terapia familiar; teoria sistêmica; escolas de terapia familiar.

\section{The Systemic Perspective for Family Clinic}

\begin{abstract}
The present text aims to outline a brief theoretical, conceptual, empirical and technological course of family studies under a systemic perspective, and to point out the consequent proposal of interventions for family clinic. Different Family Therapy Schools are presented: from schools mainly influenced by Cybernetic to those that assimilated the contributions of Constructivism and Social Constructionism. Next, comments about family research and the interest of researchers about the theme in our country are made. Finally, our opinion about the future tendency of Family Therapy in Brazil is given.
\end{abstract}

Keywords: family; familiar therapy; systemic theory; family therapy schools.

O presente texto tem por objetivo traçar uma breve trajetória teórica, conceitual, empírica e tecnológica do estudo da família na perspectiva sistêmica e apontar a consequente proposta de intervenções para a clínica da família. Ousamos ainda tentar delinear qual perspectiva futura se mostra mais viável para esse campo de conhecimento na próxima década.

\section{Um Pouco de História}

No Brasil, duas autoras, Julia Bucher-Maluschke e Terezinha Féres-Carneiro, têm contribuído sobremaneira para o resgate da história da Terapia Familiar (TF) e das contribuições da Psicanálise e sua articulação com a abordagem sistêmica (Bucher-Maluschke, 2008; Féres-Carneiro, 1996; Féres-Carneiro \& Diniz-Neto, 2008). Ambas as autoras indicam que o estudo e o interesse pela participação da família na construção dos conflitos e do sofrimento decorrente destes últimos vêm desde os primórdios das ciências psicológicas. Tanto Féres-Carneiro quanto Bucher-Maluschke concordam que a preocupação de Freud, desde o início de seus escritos, voltou-se para as relações familiares de seus pacientes, colocando a família e o indivíduo como interdependentes.

1 Aproveito a oportunidade para agradecer às grandes mestras da Terapia Familiar no Brasil, o muito que aprendi e ainda aprenderei: Julia Sursis Nobre Ferro Bucher-Maluschke, Maria Fátima Olivier Sudbrack, Maria José Esteves de Vasconcellos, Rosa Maria Stefanini de Macedo, Terezinha Féres-Carneiro.

2 Endereço para correspondência: Departamento de Clínica, Instituto de Psicologia, Universidade de Brasilia. Brasília, DF. CEP 70.910-900. E-mail: lianaf@terra.com.br.
Muitos outros autores contemporâneos, como Adler, Sullivan e Fromm-Reichman, também contribuíram no sentido de apontar as origens dos conflitos individuais nas relações familiares. Teóricos da Cibernética (como Norbert Wiener), ou movimentos terapêuticos grupais (como Pichon Riviére e as comunidades terapêuticas) participaram do movimento lento, mas definitivo, de trazer a família para a cena clínica, o que veio ocorrer sistematicamente após 1960. A família passa, então, a ser a protagonista da cena com o reconhecimento de que seu estudo auxilia a compreensão da dimensão individual do conflito. A partir daí é que se desenvolvem os modelos sistêmicos da TF.

A TF surgiu nos Estados Unidos a partir do trabalho de um grupo de pensadores e terapeutas, conforme indica Minuchin (2006/2007): Gregory Bateson e Nathan Ackerman foram os pioneiros. Entre 1960 e 1970 surgiram diferentes abordagens, métodos, clientelas e contextos do que hoje temos como o escopo da TF. O pensamento original era que a orientação teórica sistêmica era aplicável a toda estrutura humana, sem preocupação com diferenças culturais ou étnicas. Gradativamente, no entanto, foram surgindo, a partir de críticas, importantes complementos que se incorporaram a esse pensamento original: a crítica feminista à ausência da perspectiva de gênero e poder no enfoque sistêmico; a dimensão intrapsíquica que buscou recuperar o indivíduo no grupo familiar; as emoções e as heranças transgeracionais; os significados nas conversações e o lugar da família no contexto sociocultural. É importante, ainda, apontar as mudanças ocorridas na formação, na postura e na ação do terapeuta familiar, desde seu início. As mudanças vão de um terapeuta eminentemente intervencionista, a um terapeuta 
conhecedor ativo de si mesmo e dos membros da família, não neutro, mas determinado a participar. Essa trajetória de qualificação pessoal teve seu percurso entre pertinência e pertencimento (Andolfi, 1981) à significação e interpretação das narrativas da família (Anderson \& Goolishian, 1998).

Para Nichols e Schwartz (2006/2007), a abordagem individual e a familiar oferecem condições de compreensão e ajuda para a resolução de conflitos e alívio do sofrimento humano. A mudança individual favorece a mudança familiar e vice-versa. No entanto, a TF presta-se melhor ao enfrentamento terapêutico de determinados problemas interacionais (queixas entre membros da família ou entre o casal) ou problemas ligados a momentos de transição da vida familiar (como adolescência e uso de drogas). A TF traz para análise o campo de interseção dos indivíduos em família, e desta com o ambiente sociocomunitário que a circunda, enfocando sistemas, subsistemas e sistemas mais amplos em conexão.

Não é minha intenção fazer uma retrospectiva histórica da TF, mas apenas apontar breves momentos da construção teórico-metodológica que caracterizaram seu início e marcaram seu desenvolvimento posterior. Portanto, peço desculpas, desde já, pela ausência de algumas referências importantes desse percurso. É de comum reconhecimento que o Grupo de Palo Alto (Gregory Bateson, John Weakland, Don Jackson, Paul Watzlawick, entre outros) interessou-se pelo estudo da comunicação, trazendo suas observações para o campo da análise das relações humanas no cotidiano. É dessa época, entre 1960 e 1970, a descrição da comunicação do duplo vínculo. As construções teóricas iniciais da TF contaram com grande contribuição de psicanalistas que se interessaram pela observação da comunicação em famílias com membros psicóticos, como Lyman Wynne. Desse período surgem as discussões sobre o papel da emoção na interação, que cria qualidades particulares, como é o caso da pseudomutualidade ou do cerco de borracha, que foram conceitos formulados com base nas interações de famílias com membro psicótico e na análise da comunicação característica desse grupo.

O Grupo de Palo Alto trouxe ainda outras contribuições dos terapeutas Jay Haley e Virginia Satir, que apresentaram indicações práticas e técnicas como recursos para alcance de mudanças no padrão da interação familiar. Em especial, Satir trouxe o valor dos sentimentos para complementar uma racionalidade mais prevalente nesse momento (Nichols \& Schwartz, 2006/2007). Outros teóricos, como Murray Bowen e Ivan Boszormenyi-Nagy, estudaram as heranças, mitos e lealdades familiares que colaboram para a repetição de conflitos nas diferentes gerações. Já Nathan Ackerman e Carl Withaker trouxeram intensidade e valor ao manejo técnico do terapeuta. Na década de 1970 chegamos a Salvador Minuchin que foi, indiscutivelmente, uma referência de terapeuta criativo, teórico e propositor de um modelo que influencia, até hoje, desdobramentos ocorridos na TF.

Temos, portanto, a seguinte caracterização ao longo das últimas cinco décadas: década de 1960 - surge a TF, privilegiando o estudo da comunicação; décadas de 1970 e 1980 - aparecimento de escolas de TF, com ênfase na Escola Estratégica e na Escola de Milão; década de 1990 - novos enfoques interpretativos e discursivos; década de 2000 - TF voltada para a família na relação com sistemas mais amplos. Sem dúvida, podemos afirmar que permanece, em todos esses períodos, a primazia do pensamento circular para compreensão e intervenção do jogo relacional.

\section{Bases Epistemológicas e Teóricas}

A Cibernética, estudo dos mecanismos de feedback em sistemas que se autorregulam, foi o mais influente modelo teórico sobre o estudo de famílias (Nichols \& Schwartz, 2006/2007). O circuito de feedback representa o processo por meio do qual um sistema obtém uma informação necessária para seguir adiante de forma estável. Essas definições pontuam a perspectiva circular, ou circularidade, como a lente para compreensão das influências mútuas entre os membros da família. Inicialmente, os conceitos cibernéticos foram aplicados sobre a observação direta das interações ocorridas em família. O desafio foi enxergar a família além das individualidades e buscar o padrão de influência mútua que se observa nas condutas de seus membros.

Ademais, Ludwig von Bertalanffy desenvolveu um modelo teórico - a Teoria Geral dos Sistemas - que combinava conceitos de pensamento sistêmico e da biologia, e buscava sua aplicação aos seres vivos e aos sistemas sociais. Nessa proposta teórica, os organismos eram um sistema aberto interagindo todo o tempo com seu ambiente, buscando como um todo atingir um objetivo a partir de suas condições (equifinalidade), com uma reatividade que visa o equilíbrio (homeostase) e, acima de tudo, dirigindo-se a mudanças. Esses conceitos se mantiveram como referência em todas as discussões e avanços teóricos posteriores na TF (Bloch \& Rambo, 1995/1998; Nichols \& Schwartz, 2006/2007).

Nesse ponto, vale ressaltar uma formulação teórica inicial que sempre teve grande influência sobre a interpretação da dinâmica familiar, que é a função do sintoma. O surgimento de um sintoma em um membro da família pode ter uma função estabilizadora de um movimento de mudança iminente, restabelecendo, assim, uma homeostase anterior. O sintoma teria uma função homeostática. Essa compreensão fez com que se buscasse olhar o sintoma muito além da queixa individual. Poderíamos dizer que o sintoma beneficiaria a interação familiar (Nichols \& Schwartz, 2006/2007). Neuburger (1984) resumiu essa posição numa sentença: um membro familiar tem um sintoma e é um sintoma da família. Essa perspectiva conceitual, atualmente, está bastante desgastada em virtude de que o estabelecimento de uma relação causal e competitiva entre o aparecimento do sintoma e sua função reguladora pode levar a uma posição antagônica do terapeuta e da família. O terapeuta, hoje, está mais preocupado em alcançar uma relação mais colaborativa com o sistema.

Em 1995, Esteves de Vasconcellos publicou contribuições para a releitura e aprofundamento da compreensão da interação do sistema, criticando a influência da Cibernética sobre a TF, sendo aquela vista como uma perspectiva mais mecanicista, na qual a preocupação maior é com a organização do sistema. A partir de discussões epistemológicas, referenciadaz em autores como Edgar Morin, Humberto Maturana, Bradford Keeney, Marcelo Pakman, Lynn Hoffman, entre outros, Esteves de Vasconcellos articulou novos conceitos como complexidade, instabilidade, desordem e imprevisibilidade para reconhecer a manifestação de um 
"novo paradigma". Essa autora propõe que o novo paradigma, denominado de Pensamento Sistêmico, seja mais abrangente e aplicado às ciências de modo geral. Interessa-nos como essa proposição pode ser útil na ampliação do estudo dos sistemas familiares em conexão com outros sistemas sociais.

Em sua obra de 2002, Esteves de Vasconcellos apresentou formalmente sua proposta epistemológica para o estudo das interações intra e entre sistemas, observadas em famílias ou além, sendo a complexidade, a instabilidade e a intersubjetividade consideradas em contexto. Esses conceitos não são invocados como novos, mas com uma nova percepção da condição de fundantes na observação dos sistemas. A família pode ser compreendida, então, como um sistema em relação, que deve ser visto em seu contexto (um sistema em relação com outros sistemas); em sua complexidade (com interações múltiplas e diversas); em sua instabilidade (articulações e mudanças em constante andamento) e em sua intersubjetividade (realidades múltiplas decorrentes de interações). Buscamos aqui resgatar a contribuição de uma autora brasileira que tem reconhecimento nacional e internacional, apresenta uma proposição teórica e constrói uma referência que considera e integra elementos conceituais formulados em discussões epistemológicas de outras ciências, durante esse período de avanço da TF.

Para finalizar esse tópico, aponto que unidades de análise da TF sempre se concentraram em pensar a família em seu contexto; considerar a reciprocidade como influência mútua nos relacionamentos; analisar as interações e os problemas vivenciados como produto de uma causalidade circular; valorizar o processo de comunicação; conhecer a função do sintoma para a organização familiar; perceber a emergência de problemas e conflitos considerando a passagem da vida familiar por ciclos. Como veremos a seguir, novos temas e enfoques foram sendo agregados aos conceitos fundamentais, a partir de 1980: maior preocupação com o conteúdo das conversações entre os membros da família, daí o surgimento de um interesse particular na construção das narrativas familiares; conscientização das influências do gênero e da disputa de poder (aspectos preponderantes da vida social) presentes na família; reconhecimento da relação interpenetrante das características culturais, étnicas e de raça na família (McGoldrick, 1998/2003; McNamee \& Gergen, 1995/1998; Perelberg \& Miller, 1990/1994).

\section{As Escolas de Terapia Familiar e seus Conceitos}

\section{Escolas com maior influência da Cibernética e da Teoria Geral dos Sistemas}

As Escolas que receberam maior influência imediata dos conceitos da Cibernética e da Teoria Geral dos Sistemas foram as pioneiras na construção do contexto clínico do atendimento a famílias com a observação direta das interações familiares. Também preservaram o conceito básico de que $a$ família é um sistema vivo e aberto, em constante mudança. Em termos conceituais, além dessa premissa, esses teóricos enfocam a família como um grupo delimitado por fronteiras, organizado em subsistemas menores e inserido em sistemas maiores, com função autorreguladora que busca manter a homeostase que, por sua vez, tem uma função interpessoal no surgimento de um sintoma, o qual é visto como um regulador homeostático (Bloch \& Rambo, 1995/1998). A terapia é voltada para observação e ação, visando conhecer e atuar na homeostase.

O método é o da observação direta da interação familiar, buscando a modificação do padrão de comunicação, porque os conflitos são vistos como o resultado da forma de comunicação de uns membros com outros. Em termos formais, além da presença de todos os membros da família à consulta, temos o atendimento realizado por uma equipe, a qual se divide naqueles que estão em contato direto com a família (dupla terapêutica), e os que se dedicam mais à observação, mas têm uma responsabilidade compartilhada na leitura e interpretação da dinâmica familiar, bem como na condução da ação. Desde esse período, há uma inovação que diz respeito à filmagem dos atendimentos, a qual tem utilidade tanto para os terapeutas como para os membros da família, como um recurso estratégico de provocação para mudança.

Os principais grupos representantes dessa orientação metodológica específica são: a Escola de Palo Alto (Paul Watzlawick, Gregory Bateson, Carlos Sluzki, entre outros); a Escola Estrutural (Salvador Minuchin, Jorge Colapinto, entre outros); e a Escola Estratégica (Jay Haley, Cloé Madanés, entre outros). Em termos metodológicos, os teóricos baseavam suas intervenções em redefinições (definir de modo novo um comportamento antigo, dando-lhe um novo sentido) e na orientação de tarefas, que seriam realizadas pelas famílias, com o objetivo de alterar o padrão de comunicação repetitivo. Há um livro (Watzlawick, Weakland \& Fisch, 1973/1977), bem ilustrativo, da avaliação dos conflitos familiares a partir da análise dos comportamentos que estariam sustentando a repetição dos conflitos e da proposição de tarefas que teriam o poder de interferir na homeostase e criar novas respostas.

A Escola de Palo Alto propõe uma terapia breve e objetiva, procurando evidenciar os paradoxos da comunicação na família, e centrada na solução de problemas. A Escola Estratégica também conserva esses objetivos a partir da observação das regras familiares que mantêm o problema. As regras governam todo o sistema e a busca é por mudanças de segunda ordem que mostram, de fato, mudança nas regras do sistema. Uma mudança de primeira ordem traz somente uma mudança na regra do comportamento de um elemento do sistema, não sendo, portanto, o desejável. Apesar dessas proposições colocarem o terapeuta numa posição de muito poder, e esse "interventor poderoso" ser alvo de críticas, esse modelo trouxe muitas contribuições quanto ao manejo terapêutico e uso de técnicas com a família, que permanecem até hoje (Nichols \& Schwartz, 2006/2007; Wittzaele \& Garcia, 1995/1998).

A Escola Estrutural (Minuchin, 1980/1982) valoriza a estrutura familiar e segue mapeando fronteiras, regras, direção da funcionalidade familiar, padrão de organização das interações, repetições de comportamentos, coalizões, dinâmica de interação. A abordagem dá grande valor à análise e intervenção nos subsistemas, que são grupos demarcados por fronteiras internas, como o subsistema fraternal, o conjugal, o feminino, o masculino etc. As fronteiras têm ainda uma outra função que é demarcar a estrutura hierárquica. 
O terapeuta busca alterar essa estrutura com a intervenção em seus elementos, por meio de uma participação ativa que tem por objetivo alterar a hierarquia familiar e o problema relacionado a ela.

$\mathrm{O}$ aspecto metodológico inclui criatividade no trato com os membros da família, posição de liderança e autoridade, mapeamento da estrutura progressivamente ao andamento das sessões, e intervenções que seguem um plano objetivo e claro. $\mathrm{O}$ foco é permanente nas interações entre os membros da família. Duas orientações técnicas são bastante usadas: prescrição de tarefas, o que leva o ambiente terapêutico para dentro de casa, e o enfoque no sintoma por meio de sua redefinição. A afetividade também merece especial atenção.

A Escola Estratégica (Haley, 1985; Madanes, 1984) é um modelo pragmático voltado essencialmente para a clínica. Sua preocupação é com a solução do problema e com a identificação dos comportamentos que mantêm o problema. Para cada resolução de problema, são traçadas estratégias específicas. Há um plano geral, que inclui a primeira entrevista, a qual tem lugar muito importante, pois além de explorar o problema, estabelece as metas e as atribuições que cabem a todos. Progressivamente vão sendo planejadas intervenções que requerem cooperação de todos, até o estágio de resolução do problema, e uma fase posterior de manutenção dos ganhos obtidos.

\section{Conceitos complementares da Psicanálise na Terapia Familiar}

Muitos teóricos iniciais da TF eram psicanalistas e trabalharam no sentido de estabelecer complementaridade com os conceitos cibernéticos, produzindo contribuições que resgatam as histórias familiares e seus desdobramentos ao longo do tempo, isto é, resgatam a importância do processo da relação familiar e não somente o momento atual observado. Alguns terapeutas tiveram destaque nessa abordagem: Alberto Eiguer, Andre Ruffiot, Dider Anzieu, entre outros, e mais recentemente, Robert Neuburger e Pierre Segond. Esses autores resgatam a palavra nas sessões, entendem que o sintoma reflete aspectos da história passada da família e que é por meio da interpretação e releitura do significado do sintoma na história familiar que haverá mudanças. O objetivo da sessão de TF é clarear as repetições de comportamentos passados e que ainda se reproduzem no presente (Féres-Carneiro, 1996). Há um grande interesse na trama inconsciente dos sentimentos, desejos e expectativas entre os membros da família. $\mathrm{O}$ método é o da interpretação das relações e repetições, para que esse padrão se faça consciente a todos. O grupo familiar compartilha um aparelho psíquico inconsciente.

Tomo a liberdade de incluir, nesse tópico, os estudiosos dos aspectos inconscientes (e.g., segredos, mitos e transmissões geracionais) que envolvem todos os membros da família. Esses aspectos são perpetuados por meio das lealdades invisíveis (Boszormenyi-Nagy \& Spark, 1983), isto é, compromissos assumidos de forma não consciente entre os membros da família. Dentre esses autores, destaco Boszormenyi-Nagy, Helm Stierlin e Murray Bowen. O que está em jogo, nessa abordagem, é tanto a individuação como a dependência emocional que une inexoravelmente todo os membros da família em suas histórias particulares e familiares. Como cada pessoa se posiciona individualmente nessa trama, entre a história individual e a história familiar surge a condição de realizar e manter a separação com relação à dependência emocional que une a todos os membros da família.

O conceito de transmissão geracional, discutido por Murray Bowen, trata dos processos de projeção familiar repetidos de geração a geração, permitindo, ou não, níveis de diferenciação. Outros conceitos, como lealdade e parentalização, desenvolvidos por Boszormenyi-Nagy, tratam dos processos inconscientes que formulam compromissos entre os membros da família, ao longo de gerações e que, em última análise, visam garantir a união do sistema. A família, durante todo o tempo, administra a tensão entre união e distanciamento emocional, proporcionando separação e crescimento funcional no devido momento. A escuta é o principal fator nessa abordagem, além da valorização da história familiar que identifica as relações afetivas precoces de todos os membros nas diferentes gerações.

Para finalizar esse tópico, aponto a posição de FéresCarneiro (1996) e Bucher-Maluschke (2008), que enfatizam o valor complementar da influência psicanalítica na clínica da família. Além disso, o estudo das influências transgeracionais sobre o surgimento de determinados sintomas na família, como abuso de substâncias químicas ou violência intrafamiliar sexual, beneficia-se extremamente das contribuições advindas da abordagem transgeracional (Penso \& Costa, 2008).

\section{A Escola de Milão}

Novamente, tomo a liberdade de organizar a construção do contexto clínico da família, ressaltando, em especial, as contribuições da Escola de Milão. Seus vários teóricos Mara Selvini Palazzoli, Gianfranco Cecchin, Luigi Boscolo e Giulana Prata - tiveram grande influência dos conceitos das escolas iniciais, anteriormente expostos. Porém, esses autores foram além e propuseram conceitos que inovaram e formaram diretrizes teórico-metodológicas de grande abrangência sobre os terapeutas familiares de todos as épocas e orientações teóricas, tais como: questionamento circular, conotação positiva e elaboração de hipóteses (Féres-Carneiro, 1996). Esse grupo preocupou-se com apresentação de recursos e ações que envolvessem todos os membros da família. A elaboração de hipótese inclui a ideia de que o terapeuta e os membros da família estão construindo e "testando" explicações sobre o que se passa com a família. O questionamento circular reflete o conceito de circularidade, de que os sistemas vivos são caracterizados por formações de círculos relacionais. A neutralidade é a posição de que o sistema deve ser visto em todas as suas partes, e todas têm a mesma importância na sua expressão. Na prática é fazer aliança com todos os membros da família. Além do valor da equipe como um importante recurso no atendimento, a Escola de Milão trouxe questionamento sobre intervalo entre as sessões, como um outro recurso terapêutico (Boscolo, Cecchin, Hoffman \& Penn, 1993). Nichols \& Schwartz (2006/2007) consideram que a Escola de Milão pode ser vista como estratégica (na origem de seus conceitos e prescrições) e com ênfase na 
adoção de rituais, que são ações prescritas para dramatização da conotação positiva.

\section{Aquisição de conceitos sociais na Terapia Familiar}

Ao longo do tempo, o estudo das famílias incorporou temas e conceitos com forte ênfase social, como o feminismo e a rede social. A leitura sistêmica da família ressalta mais o conjunto e menos as partes. Alguns temas sociais, como atenção às relações de gênero, vieram valorizar essas partes e os indivíduos com posição social diferentes dentro do todo. $\mathrm{O}$ papel da mulher, o patriarcado, os condicionamentos sociais da maternidade/paternidade passaram a receber estudos particularizados. Com esse avanço, foram trazidos para a leitura das relações familiares, temas como a submissão da mulher, a vitimização de mulheres e crianças e a responsabilidade social e ética decorrentes dessas observações, bem como a questão do poder diferenciado entre homens e mulheres, entre adultos e crianças e/ou adolescentes numa sociedade machista (Saffioti, 1997).

A perspectiva feminista trouxe críticas importantes à adoção de conceitos cibernéticos. A complementaridade (diferença de posicionamento entre homem e mulher) não contempla a desvantagem que a mulher tem em relação ao homem em nossa sociedade (Goodrich, Rampage, Ellman \& Halsted 1988/1990; Rampage \& Avis, 1995/1998). Do mesmo modo, outros conceitos como circularidade e neutralidade tiveram suas formulações questionadas, pois a falta de apontamento dessas desigualdades sociais no contexto da terapia pode mascarar o valor desse aspecto e promover a perpetuação dos comportamentos e ações de submissão da mulher e poder do homem. Uma consequência dessa mudança se fez nas propostas metodológicas para trabalhos com violência intrafamiliar, violência conjugal e alcoolismo, nos quais uma dimensão política dessas condições tem que ser considerada. Não se trata de uma nova escola, nem de arcabouço técnico ou metodológico, mas da inserção da questão de gênero nesse contexto.

$\mathrm{O}$ conceito de rede social foi desenvolvido na década de 1960, a partir dos trabalhos de Ross Speck e Carolyn Attneave, nos Estados Unidos e Canadá, na área da psiquiatria, com famílias de psicóticos que reuniam graves condições de reintegração do paciente. Hoje, a intervenção em rede constitui-se numa ação bastante usada na Bélgica, Itália e Argentina, além dos países de origem, tendo sido definitivamente incorporada às intervenções com famílias. Os trabalhos são, prioritariamente, realizados junto a comunidades de pacientes psicóticos e toxicômanos e populações de baixa renda (Speck, 1987/1989). A rede é a tribo à qual o indivíduo pertence. O princípio que rege a formação da rede é o da mobilização do relacionamento natural das famílias como sistema de suporte para as mesmas. Esse sistema natural em volta da família é um suporte mais potente do que a responsabilidade profissional.

Speck (1987/1989) enfocou o conceito de rede social no contexto clínico, propondo uma intervenção enérgica que seria oferecida à família somente quando outros métodos não tivessem produzido resultados. Essa proposta consistia num encontro entre a equipe terapêutica (o chefe, técnicos em dinâmicas de grupo e consultores), a família e cerca de mais ou menos 40 pessoas, escolhidas, pela família, entre conhecidos, parentes, vizinhos e amigos, com o objetivo de encontrar soluções.

Com relação a trabalhos comunitários com populações menos favorecidas economicamente, Pluymarkers (1987/1989) enfoca a importância da rede social na abordagem de problemas no campo da exclusão social. Esse trabalho de rede é importante na medida em que mantém as pessoas e famílias conscientes da dimensão coletiva, das implicações socioeconômicas dos problemas, no sentido de questionar os trabalhos sociais que visam ajudar, mas terminam por acelerar a exclusão dos envolvidos no problema. Há cerca de 15 anos atrás, Dabas (1995) descreveu uma experiência de trabalho com multifamílias, que enfatizou uma abordagem descentrada da função do especialista, apoiando-se na capacidade autogestiva dos grupos. Esse trabalho visava potencializar as redes de solidariedade entre pessoas que compartilhavam problemas semelhantes, os quais incluíam quadros de exclusão resultantes de um progressivo processo de desfiliação. A valorização da construção e/ou reconstrução da rede social desenvolve a capacidade autorreflexiva e autocrítica, otimiza a organização autogestiva e implica mudanças na subjetividade individual, produzindo modificações na família e no meio social. Aun, Esteves de Vasconcellos e Coelho $(2006,2007)$ lançaram uma obra, em dois volumes, na qual explicitam, propõem e descrevem casos clínicos a partir de uma abordagem psicossocial de famílias em grave sofrimento e com grande prejuízo em sua inserção social. A proposta é de um atendimento fundamentado na perspectiva sistêmica e da mobilização da rede social de pertencimento dessa família. O valor maior dessa proposição é que se faz no contexto brasileiro, considerando as condições de sobrevivência e precariedade de recursos sociais e comunitários de nossas famílias, e exemplifica passos práticos de mobilização e atuação da rede.

\section{Linguagem e significados na Terapia Familiar}

Os estudos sobre a linguagem tiveram influência sobre a intervenção com famílias, configurado no surgimento da Abordagem Narrativista (White, 1997). Essa abordagem reflete as construções teóricas ditas pós-modernas e preocupase com o processo da construção da história e "verdade" familiar, e como esses significados são construídos.

Para a configuração da Abordagem Narrativista, conceitos advindos da Biologia (Maturana Romesín, 1995/1998), na interface com os processos comunicacionais, e a inseparabilidade entre o observador e o observado (von Foerster, 1988) foram incorporados, passando-se a dar atenção aos processos cognitivos presentes nas interações familiares. Duas correntes teóricas forneceram subsídios para essa abordagem: O Construtivismo e o Construcionismo Social. O Construtivismo propôs a redescoberta do processo libertador do diálogo (Anderson \& Goolishian, 1998). A abordagem Narrativista visa que a família explore novos significados e sentidos para os fatos em andamento, constituindo-se em um avanço muito grande e crítico em relação à observação privilegiada do comportamento, característica das abordagens 
anteriores. A partir do Narrativismo, toma-se a direção da percepção e interpretação dos fatos e do sofrimento inerente, pela ótica de todos da família. A percepção é recíproca e a linguagem cria soluções (Nichols \& Schwartz, 2006/2007). O Construcionismo Social trouxe a reconsideração do papel da linguagem no mundo social e na relação familiar. As interações são construídas no processo de interrelação, mediado, principalmente, pela linguagem, ou seja, pelo modo de conversar. Os eventos da história familiar têm que ser vistos em função do momento histórico, social e cultural. A ação cooperativa entre as pessoas marca o processo de relação familiar e a construção das saídas dos conflitos.

Em síntese, podemos dizer que o Construtivismo enfatiza a concepção de que as pessoas criam suas realidades e de que a experiência é, primordialmente, subjetiva. O Construcionismo Social enfatiza que as pessoas em interação criam significados advindos da percepção particular e também das experiências no âmbito social, e essas experiências são intersubjetivas, narradas e interpretadas nesse contexto. Os significados são construídos na interação social e não mais na origem individual (Elkaïm, 1995/1998; Guimarães \& Costa, 2002; McNamee \& Gergen, 1995/1998). Apesar de o Construcionismo Social dar ênfase a processos mais sociais e o Construtivismo, a processos mais individuais, ambos contribuíram de forma complementar para a TF, colocando a família como um sistema sociocultural e linguístico.

Retomando a Abordagem Narrativista, seu princípio central é que nossas ações e comportamentos são efeitos concretos dos significados que damos às nossas experiências, e esses significados estão expressos nas histórias que contamos, para outros, sobre nós mesmos. Essas narrativas têm que ser dimensionadas em seu contexto social e cultural. Dessa forma, cria-se um sistema de significados no qual estamos imersos. Precisamos ir além e exteriorizar esses significados. Isso ocorre na conversação, e é por meio dela e de perguntas desconstrutivas que podemos reconstruir esses significados (Guimarães \& Costa, 2002; White, 1997; Zimmerman \& Dickerson, 1995/1998), tomando-se a direção de que cada um construa uma outra alternativa de conhecimento próprio. Essa abordagem se configura para mudanças individuais e interacionais. Uma conversação que seja criativa, curiosa, desconstrutiva e reconstrutiva baseia-se na interpretação dos significados, isto é, na hermenêutica (Anderson \& Goolishian, 1998; McNamee \& Gergen, 1995/1998; Nichols \& Schwartz, 2006/2007). São as narrativas presentes nas conversações que encadeiam e dão sentido às experiências vividas e oferecem outros sentidos e, assim, outras "verdades” poderão ser construídas (Guimarães \& Costa, 2002).

\section{As Transformações no Contexto Sociocomunitário e a Resposta da Terapia Familiar}

Desde a década de 1990 tem havido um lento, mas inexorável, direcionamento das intervenções clínicas para o contexto comunitário. O Instituto Brasileiro de Geografia e Estatística - IBGE (2003) informa que em 2003, 32\% dos municípios brasileiros viviam na pobreza absoluta e que em 77\% dos municípios do Nordeste, mais da metade da população vivia na pobreza. Em função dessas condições econômicas precárias, tem havido iniciativas no sentido de viabilizar o acesso dessas populações ao contexto clínico e, desse modo, tem ocorrido adaptações de métodos clínicos para contextos de comunidades de baixa renda. A Terapia Comunitária (TC) foi criada por Adalberto de Paula Barreto - médico, psiquiatra, antropólogo, professor de Psiquiatria da Universidade Federal do Ceará - e, ainda que não voltada para o grupo familiar, tem sua base teórica sistêmica, sendo seu criador, ele mesmo, um terapeuta familiar sistêmico. Outro método, o Grupo Multifamiliar (GM), já bastante divulgado, está, cada vez mais, sendo adotado por instituições públicas que atendem famílias carentes, como é o caso dos CRAS (Centro de Referência em Assistência Social) ou dos CREAS (Centro de Referência Especializada de Assistência Social). Ambas instituições pertencem às ações de política pública do Ministério do Desenvolvimento Social e Combate à Fome (MDS).

A TC nasceu há 20 anos (Barreto, 2007), a partir de uma iniciativa do Departamento de Saúde Comunitária da Universidade Federal do Ceará, com apoio do Centro de Direitos Humanos do Pirambú (favela de Fortaleza) e do Movimento Integrado de Saúde Mental Comunitária. Grandesso (2007) situa a TC na perspectiva sistêmica, identificando seu objeto de intervenção como o grupo e a comunidade, e contemplando em sua organização e método, os aspectos apontados anteriormente por Esteves de Vasconcellos (2002): complexidade, imprevisibilidade e intersubjetividade. Além disso, essa autora indica a TC como o espaço de diálogo e conversas, no qual histórias são reconstruídas pela ativa participação de todos os presentes. A TC compreende os distúrbios das populações excluídas em três categorias: do abandono, da insegurança e da baixa autoestima. $O$ contexto para atenção a esses problemas, considerando populações desassistidas, é o comunitário. A TC encontra-se, atualmente, difundida em todo o território nacional, tendo sido preconizada pela Secretaria Nacional de Políticas sobre Drogas, vinculada diretamente à Presidência da República, que edita uma cartilha denominada "A Prevenção do Uso de Drogas e a Terapia Comunitária" (SENAD, 2010).

O GM surgiu na década de 1950 e foi chamado inicialmente de Terapia de Múltiplos Grupos Familiares, por Peter Laquer (Nichols \& Schwartz, 2006/2007). Essa abordagem é uma adaptação da técnica de grupo ao tratamento de famílias e foi criada a partir de famílias de pacientes psicóticos (Laquer, 1973/1983). Bowen (1976) descreveu os primeiros resultados sobre a reunião de famílias num contexto clínico, observando que estas se mostravam mais à vontade estando reunidas e que havia maior focalização nas interações familiares. As famílias desenvolveram mudanças 50\% mais rápidas do que famílias semelhantes que eram vistas isoladamente. Laquer (1973/1983) descreve os GM como grupos abertos, com famílias ingressando ou deixando o grupo conforme o necessário. As famílias são reunidas durante 1 hora e 30 min em sessões semanais, frente a uma equipe terapêutica que inclui terapeuta, coterapeuta e observadores. A seleção das famílias é feita com base na similaridade na intensidade dos problemas (Bowen, 1976) ou, então, de forma aleatória, dependendo das queixas. O principal ganho dessa forma de intervenção é quanto à aprendizagem de novas formas de comportamento pela pressão ou aprovação do grupo, 
e as mudanças se dão por semelhança e identificação. Por semelhança, quando as famílias presenciam, em outras, seus conflitos, e por identificação, quando pais aprendem com outros pais, mães com outras mães, as soluções já encontradas. As famílias assumem o papel de coterapeutas, na medida em que já alcançaram mudanças e, desse modo, funcionam como modelos, criando um foco permanente de excitação, já que sempre existem famílias em estágios diferentes. Um dado considerado relevante por Laquer (1976) é que, na convivência com outras famílias, há a quebra do rígido código familiar e dos silenciamentos e, assim, fica evidente o conflito intrafamiliar. Essa quebra pode, ainda, levar ao surgimento da cooperação. Várias experiências vêm sendo realizadas com populações de baixa renda e com populações com problemas específicos. É importante assinalar que, na atualidade, o MDS vem organizando e sistematizando sua política de assistência às famílias carentes, por meio de documentos que preconizam o atendimento em grupo familiar. O documento do Serviço de Proteção e Atendimento Integral à Família - Paif (MDS, 2010) e o Guia de Orientação n ${ }^{\circ} 1$ (CREAS, 2010) indicam que a assistência às famílias deve ser organizada e proposta em grupos, mais especificamente, "grupos de famílias".

Ambas as abordagens têm sua praticidade indicada para nosso contexto de famílias com carências financeiras, como foi apontado nos dados do IBGE (2003). Queremos aqui ressaltar que essas iniciativas respondem de forma viável às necessidades da população de baixa renda familiar e vêm assumindo um papel fundamental para a viabilização dessas políticas públicas que o país deve há muito tempo para essas famílias.

\section{Proposta Metodológica para o Trabalho com Famílias no Contexto Comunitário}

Em 1998, a autora deste texto defendeu sua Tese de Doutorado sobre o tema família, com uma proposição metodológica de Reuniões Multifamiliares para atendimento comunitário a famílias, numa perspectiva de construção de contexto clínico na comunidade (Costa, 1998). Desde então, essa perspectiva vem oferecendo outras possibilidades de adaptação, e têm sido publicados outros trabalhos descrevendo essa trajetória, a partir de um projeto de pesquisa interinstitucional (Costa, 2002) que reúne duas universidades - Universidade de Brasília e Universidade Católica de Brasília. Vários resultados decorrentes desse projeto já foram publicados: Costa, Almeida, Ribeiro e Penso (2009), Costa, Penso, Almeida e Ribeiro (2008), entre outros títulos.

Em termos teóricos, o GM tem como referência os aportes: (a) da Psicologia Comunitária, que visa o trabalho em grupo, preocupa-se com a adaptação da Psicologia Clínica na comunidade (Mejias, 1995) e valoriza a equipe com diferentes saberes, científicos e populares (Santos, 1999); (b) da Terapia Familiar, em que a família é vista "como o cliente" e a relação é o ponto focal do trabalho, sempre numa perspectiva contextual (Minuchin, Colapinto \& Minuchin, 1998/1999); (c) do Sociodrama, em que o grupo é o protagonista e a ação protagônica grupal é o objetivo (Moreno, 1959/1993); e (d) da Teoria das Redes Sociais, que enfoca a interação huma- na com a troca de experiências, compreendendo-se que as relações já existentes nas redes naturais dos sujeitos devem ser preservadas (Sluzki, 1994/1996).

Cada sessão do GM dura em média 3 horas e sua programação segue um calendário quinzenal. Cada encontro dividese em três momentos distintos e interligados: aquecimento, discussão e conclusão. Essa organização segue orientação metodológica da sessão psicodramática (Gonçalves, Wolff \& Almeida, 1988), que indica três etapas: aquecimento, dramatização e compartilhamento. $\mathrm{O}$ 'aquecimento' tem por objetivo integrar o grupo e estimular a discussão do tema daquele dia (são usados jogos dramáticos). A 'discussão' visa aprofundar a conversação sobre o tema, desenvolver a capacidade de reflexão sobre o assunto por meio de perguntas reflexivas (Anderson \& Goolishian, 1998) e acolher o sofrimento psicológico advindo das identificações com o tema (são propostos subgrupos para melhor aproveitamento da conversação). A 'conclusão' sintetiza as opiniões sobre o tema discutido, avalia a aprendizagem sobre o tema e formula sugestões práticas às famílias (cada encontro termina com um ritual de compromisso mútuo).

A proposta do GM tem sido adaptada a diversos contextos envolvendo famílias encaminhadas pela justiça e com atendimento sob obrigação, adolescentes em cumprimento de medida socioeducativa e suas famílias, famílias com situação de violência sexual envolvendo crianças e adolescentes e famílias com adolescentes ofensores sexuais (Costa \& Penso, 2010). Cada uma das adaptações para esses diferentes contextos contém sugestão de temas específicos ligados à complexidade de cada circunstância. Para o contexto de atendimento comunitário, os temas são: família, violência, escolarização, profissionalização dos jovens e drogas, assim como temas de interesse da comunidade ou sugeridos pela instituição parceira. Os temas para o contexto de adolescentes em cumprimento de medida socioeducativa consistem em: família, adolescência, drogas, escola, significado da medida socieducativa e relação com o sistema judicial. No contexto de crianças e adolescentes violentados sexualmente são abordados os seguintes temas: proteção à criança, autoestima, dimensão transgeracional da violência, responsabilização dos pais (e dos adultos) pela proteção das crianças e projeto de compromisso futuro de proteção. E para o contexto de adolescentes ofensores sexuais, o temas são: eu, adolescente, protejo outras crianças mas ainda preciso de proteção; minha sexualidade está desabrochando; a violência sexual contra criança é crime e uma violência; preciso conhecer e mudar a violência na minha família; pretendo namorar bastante.

Os participantes do GM apontam que as relações grupais daqueles que têm vivências e sentimentos semelhantes entre si, ou mesmo que se conheceram dentro do grupo, é um dos aspectos apontados como vantagens para o desenvolvimento das atividades. Percebemos que a oportunidade das mulheres (ou mães) falarem entre si possui um poder de apoio e reforço para uma série de iniciativas e decisões que são necessárias ao prosseguimento das ações que envolvem famílias que têm um membro com pendência na justiça, como é o caso dos adolescentes em conflito com a lei ou das crianças e/ou adolescentes vitimizados sexualmente. Um ponto sempre enfatizado pelas mães é sobre o valor de uma intervenção clara 
e precisa, ou de uma orientação, realizada pelos profissionais que coordenam o grupo.

\section{A Pesquisa em Terapia Familiar no Brasil}

Os Anais do XIII Simpósio de Pesquisa e Intercâmbio Científico em Psicologia identificam quatro grupos de pesquisa da Associação Nacional de Pesquisa e Pós-Graduação em Psicologia - ANPEPP (2010) na área de família. Esses grupos abrangem professores e pesquisadores do norte ao sul do país, perfazendo 64 pesquisadores. Dos quatro grupos, três dedicam-se à pesquisa clínica com famílias numa perspectiva sistêmica e um grupo volta-se mais para a pesquisa em família numa perspectiva da Psicologia do Desenvolvimento. Sem a pretensão de elaborar uma pesquisa bibliográfica para comprovação de trabalhos publicados, penso que desde a década de 1980 tem havido um crescimento significativo de contribuições para o estudo de família que se preocupam em identificar e descrever os modos e problemas de interação familiar características de nosso país. Temos publicações sobre trabalhos clínicos e sobre organização familiar e do casal, estudos de gênero, estudos focando problemáticas mais específicas (e.g., drogadição, violência sexual, violência doméstica ou psicose) ou, ainda, interligando aspectos culturais comunitários e metodológicos, e estudos sobre problemas da atualidade (e.g., violência e famílias no contexto jurídico). $\mathrm{O}$ mais importante é que há, de fato, uma intenção de se estudar a família considerando nosso contexto e complexidade própria. Um exemplo dessa direção encontra-se no estudo de Macedo (2004) que, após traçar uma proposta de compreensão do ciclo de vida da família paulista e paulistana, pretende ampliar para o conhecimento do ciclo de vida da família brasileira.

O campo de pesquisa sobre a família tem nas universidades brasileiras uma consolidação que é evidente nos dias de hoje, não só nas universidades federais como nas particulares. Essas pesquisas têm sido orientadas para a clínica, para as intervenções psicossociais, questões de gênero presentes em famílias de classe média e baixa renda, organizações familiares fortemente influenciadas pela cultura e famílias com quadro de doenças crônicas ou agudas. O panorama das pesquisas tem recebido contribuições de muitas áreas: Psicologia, Serviço Social, Antropologia, Medicina, Enfermagem, Sociologia, na perspectiva sistêmica ou não. O importante é que os aspectos da intimidade familiar e conjugal vêm se desvelando, além das mudanças nas relações da família e do casal. No entanto, há um hiato entre a realização das pesquisas e o acesso que a população, de um modo geral, pode ter desses resultados. Penso que, gradativamente, essa falha poderá ser minimizada, na medida em que as publicações forem disponibilizando seus textos via internet.

\section{Desafios Futuros da Terapia Familiar em Nossa Realidade}

Atuamos num país imenso, com grandes dificuldades econômicas e com enormes áreas de muita pobreza. Precisamos pensar em metodologias que se adaptem à nossa realidade $\mathrm{e}$ possam oferecer atendimento clínico ou psicossocial às famílias que possuem grandes diferenças em suas necessidades e características. Isso implica avanços nos delineamentos das pesquisas, no sentido de proporcionar conhecimento de aspectos de dinâmicas familiares que estão ainda muito obscuros porque refletem modos de vida da população família ainda distantes dos interesses dos pesquisadores. Por exemplo: o ciclo de vida da família brasileira, as configurações familiares rompidas em razão de migração, os vínculos afetivos inerentes à realidade brasileira, incestos travestidos de valor cultural etc.

O estudo da família é um item presente no currículo dos cursos de Psicologia e essa vantagem deve ser acrescida de uma formação específica voltada para nossa realidade, assim como ocorre com a formação dada nos cursos de especialização em Terapia Familiar. Penso que o terapeuta de família, no Brasil, deva ser muito criativo para dar conta de uma diversidade de valores e diferentes modos de organização que o país possui, em função de sua área geográfica de grande dimensão e diversidade. Nesse sentido, penso que a formação em Terapia Familiar deva orientar seu currículo para o atendimento comunitário, criando modos de intervir que reflitam os recursos locais e as competências de vários profissionais que colaboram com a comunidade.

Com relação à intervenção terapêutica, a clínica da família está diante do desafio de atuar considerando a família em dependência e/ou vinculação com sistemas mais amplos, como é a situação das famílias pertencentes a classes sociais com maior prejuízo econômico. É preciso, ainda, que o conhecimento da dinâmica familiar na perspectiva sistêmica seja melhor divulgado nos sistemas decisórios, como exemplo, a Justiça. Neste ano de 2010, temos tido várias iniciativas de leis que pretendem regular a intimidade da família, como o projeto de lei que proíbe agressão física a crianças. As decisões do judiciário que se dirigem a famílias dependem de um conhecimento específico que ofereça soluções que levem em conta a complexidade das relações familiares. Da mesma forma, o conhecimento da família necessita ser ampliado e valorizado igualmente nos contextos de cuidado à infância e à adolescência, por exemplo, os contextos da escola e da medicina. Em março de 2010, aconteceu em Buenos Aires o XVIII World Family Therapy Congress da International Family Therapy Association (IFTA). Nessa ocasião, pudemos constatar o quanto nós, terapeutas de família brasileiros, estamos sintonizados com os avanços teóricos e metodológicos do estudo e do trabalho terapêutico com famílias. É claro que também constatamos o quanto o tema continua longe dos incentivos financeiros e financiamentos para pesquisas e experimentações de inovações técnicas. Porém, é inegável o potencial criativo que o terapeuta familiar brasileiro possui para atender a famílias em circunstâncias sociais e culturais tão diversas.

Finalmente, percebemos que cada vez mais profissionais estão interessados em conhecer e atuar com famílias. Esperamos que esse contingente possa integrar o grupo já existente de terapeutas e pesquisadores de famílias e, assim, colaborar no aprofundamento das questões e das ações com as famílias. 


\section{Referências}

Anderson, H., \& Goolishian, H. (1998). O cliente é o especialista: a abordagem terapêutica do não-saber. Em S. McNamee \& K. J. Gergen (Orgs.), A terapia como construção social (C. O. Dornelles, Trad.) (pp. 34-50). Porto Alegre: Artes Médicas. (Trabalho original publicado em 1995)

Andolfi, M. (1981). A terapia familiar. Lisboa: Vega.

Associação Nacional de Pesquisa e Pós-Graduação em Psicologia - ANPEPP (2010). Anais do XIII Simpósio de Pesquisa e Intercâmbio Cientifico em Psicologia. Fortaleza: ANPEPP.

Aun, J. G., Esteves de Vasconcellos, M. J., \& Coelho, S. V. (2006). Atendimento sistêmico de famílias e redes sociais. Vol. 1: fundamentos teóricos e epistemológicos. Belo Horizonte: Ophicina de Arte \& Prosa.

Aun, J. G., Esteves de Vasconcellos, M. J., \& Coelho, S. V. (2007). Atendimento sistêmico de famílias e redes sociais. Vol. 2: o processo de atendimento sistêmico. Belo Horizonte: Ophicina de Arte \& Prosa.

Barreto, A. de P. (2007). As dores da alma dos excluídos no Brasil e a terapia comunitária. Em M. Grandesso \& M. R. Barreto (Orgs.), Terapia comunitária. Tecendo redes para a transformação social. Saúde, educação e políticas públicas (pp. 19-26). São Paulo: Casa do Psicólogo.

Bloch, D. A., \& Rambo, A. (1998). O início da terapia familiar: temas e pessoas. Em M. Elkaïm (Org.), Panorama das terapias familiares, Vol. 1 (E. C. Heller, Trad.) (pp. 17-56). São Paulo: Summus. (Trabalho original publicado em 1995)

Boscolo, L., Cecchin, G., Hoffman, L., \& Penn, P. (1993). A terapia familiar sistêmica de Milão. Conversações sobre teoria e prática (C. A. Molina-Loza \& C. Sutter, Trads.). Porto Alegre: Artes Médicas. (Trabalho original $\mathrm{s} / \mathrm{d}$ )

Boszormenyi-Nagy, I., \& Spark, G. M. (1983). Lealtades invisibles. Buenos Aires: Amorrortu.

Bowen, E. (1976). Principles and techniques of multiple family therapy. Em P. Guerin Jr. (Ed.), Family therapy: Theory and practice (pp. 388-404). New York: Gardner.

Bucher-Maluschke, J. S. N. F. (2008). Do transgeracional na perspectiva sistêmica à transmissão psíquica entre as gerações na perspectiva da psicanálise. Em M. A. Penso \& L. F. Costa (Orgs.), A transmissão geracional em diferentes contextos. Da pesquisa à intervenção (pp. 76-96). São Paulo: Summus.

Centro de Referência Especializado da Assistência Social CREAS (2010). Guia de Orientação $n^{\circ} 1$. Retirado em 18/08/2010, de www.mds.gov.br.

Costa, L. F. (1998). Reuniões multifamiliares: uma proposta de intervenção em psicologia clínica na comunidade. Tese de Doutorado, Universidade de São Paulo, São Paulo.

Costa, L. F. (2002). Violência intrafamiliar: construção de metodologia de grupos multifamiliares no contexto do abuso sexual infantil (Projeto de pesquisa). Brasília: Departamento de Psicologia Clínica, Universidade de Brasília.

Costa, L. F., Almeida, T. M. C., Ribeiro, M. A., \& Penso, M. A. (2009). Grupo multifamiliar: espaço para a escuta das famílias em situação de abuso sexual. Psicologia em Estudo (Maringá), 14, 21-30.

Costa, L. F., Penso, M. A., Almeida, T. M. C., \& Ribeiro, M. A. (2008). "A justiça é demorosa, burra e cega”. Percepções de famílias sobre a dimensão jurídica dos crimes de abusos sexual. Boletim de Psicologia (São Paulo), LVIII, 85-102.
Costa, L. F., \& Penso, M. A. (2010). O grupo multifamiliar nas situações de violência sexual contra crianças e adolescentes. Em C. Ladvocat (Org.), Psicologia: campo de atuação, teoria e prática. São Paulo: Book Link.

Dabas, L. N. (1995). A intervenção em rede. Nova Perspectiva Sistêmica, 6, 5-18.

Elkaïm, M. (1998). Construtivismo, construcionismo social e técnicas narrativas: limites da teoria sistêmica? Em M. Elkaïm (Org.), Panorama das terapias familiares, Vol. 2 (E. C. Heller, Trad.) (pp. 225-251). São Paulo: Summus. (Trabalho original publicado em 1995)

Esteves de Vasconcellos, M. J. (1995). Terapia familiar sistêmica. Bases cibernéticas. Campinas: Psy.

Esteves de Vasconcellos, M. J. (2002). Pensamento sistêmico. O novo paradigma da ciência. Campinas: Papirus.

Féres-Carneiro, T. (1996). Terapia familiar: das divergências às possibilidades de articulação dos diferentes enfoques. Psicologia: Ciência e Profissão, 16, 38-42.

Féres-Carneiro, T., \& Diniz-Neto, O. (2008). De onde viemos? Uma revisão histórico-conceitual da psicoterapia de casal. Psicologia: Teoria e Pesquisa, 24, 487-496.

Goodrich, T. J., Rampage, C., Ellman, B., \& Halsted, K. (1990). Terapia feminista da família (R. M. Garcia, Trad.). Porto Alegre: Artes Médicas. (Trabalho original publicado em 1988)

Gonçalves, C. S., Wolff, J. R., \& Almeida, W. C. (1988). Lições de psicodrama. São Paulo: Ágora.

Grandesso, M. (2007). Terapia comunitária: uma prática pósmoderna crítica. Considerações teórico-metodológicas. Em M. Grandesso \& M. R. Barreto (Orgs.), Terapia comunitária. Tecendo redes para a transformação social. Saúde, educação e politicas públicas (pp. 181-190). São Paulo: Casa do Psicólogo.

Guimarães, F. L., \& Costa, L. F. (2002). Clínica psicológica do adolescente: do sistema à abordagem narrativista. Paidéia. Cadernos de Psicologia e Educação (Ribeirão Preto), 12, 163-174.

Haley, J. (1985). Trastornos de la emancipación juvenil y terapia familiar. Buenos Aires: Amorrortu.

Instituto Brasileiro de Geografia e Estatística - IBGE (2003). Mapa da pobreza e desigualdade 2003. Retirado em 15/07/2010, de http://www.ibge.gov.br/home/presidencia/noticias/noticia visualiza.php?id_noticia=1293\&id_pagina=1.

Laquer, H. P. (1976). Multiple family therapy. Em P. Guerin Jr. (Ed.), Family therapy. Theory and practice (pp. 405-416). New York: Gardner.

Laquer, P. (1983). Terapia familiar múltipla: perguntas e respostas. Em D. A. Bloch (Coord.), Técnicas de psicoterapia familiar. Uma estrutura conceitual (pp. 93-107). São Paulo: Atheneu. (Trabalho original publicado em 1973)

Macedo, R. M. S. de (2004). O ciclo vital da família no Brasil (Projeto de Pesquisa). São Paulo: Pontifícia Universidade Católica de São Paulo.

Madanes, C. (1984). Terapia familiar estratégica. Buenos Aires: Amorrortu.

Maturana Romesín, H. (1998). Da biologia à psicologia (J. A. Llorens, Trad). Porto Alegre: Artes Médicas. (Trabalho original publicado em 1995)

McGoldrick, M. (2003). Novas abordagens da terapia familiar. Raça, cultura e gênero na prática clínica (M. Lopes, Trad.). São Paulo: Roca. (Trabalho original publicado em 1998)

McNamee, S., \& Gergen, K. J. (Orgs.) (1998). A terapia como construção social (C. O. Dornelles, Trad.). Porto Alegre: Artes Médicas. (Trabalho original publicado em 1995) 
Mejias, N. P. (1995). A atuação do psicólogo: da clínica para a comunidade. Cadernos de Psicologia (São Paulo), 1, 32-43.

Ministério do Desenvolvimento Social - MDS (2010). Serviço de proteção e atendimento integral à família (Paif). Retirado em 18/08/2010, de http://www.mds.gov.br/assistenciasocial/ protecaobasica/servicos/protecao-e-atendimento-integral-a-familiapaif.

Minuchin, S. (1982). Famílias: funcionamento \& tratamento (J. A. Cunha, Trad.). Porto Alegre: Artes Médicas. (Trabalho original publicado em 1980)

Minuchin, S. (2007). Prefácio. Em M. P. Nichols \& R. C. Schwartz, Terapia familiar: conceitos e métodos ( $7^{\mathrm{a}}$ ed.) (M. A. V. Veronese, Trad.) (pp. v-vii). Porto Alegre: Artes Médicas. (Trabalho original dessa edição publicado em 2006)

Minuchin, P., Colapinto, J., \& Minuchin, S. (1999). Trabalhando com familias pobres (M. F. Lopes, Trad.). Porto Alegre: Artes Médicas. (Trabalho original publicado em 1998)

Moreno, J. L. (1993). Psicoterapia de grupo e psicodrama (A. C. M. Cesarino Filho, Trad.) ( $2^{\mathrm{a}}$ ed.). Campinas: Psy. (Trabalho original publicado em 1959)

Neuburger. R. (1984). L'autre demand. Psychanalyse et thérapie familiale systhémique. Paris: ESF.

Nichols, M. P., \& Schwartz, R. C. (2007). Terapia familiar. Conceitos e métodos ( $7^{\mathrm{a}} \mathrm{ed}$.) (M. A. V. Veronese, Trad.). Porto Alegre: Artes Médicas (Trabalho original dessa edição publicado em 2006)

Penso, M. A., \& Costa, L. F. (2008). A transmissão geracional em diferentes contextos. Da pesquisa à intervenção. São Paulo: Summus.

Perelberg, R. J., \& Miller, A. (Orgs.) (1994). Os sexos e o poder nas famílias (M. C. B. Fernandes, Trad.). Rio de Janeiro: Imago. (Trabalho original publicado em 1990)

Pluymarkers, J. (1989). Red y práctica de barrio. Em M. Elkaïm (Org.), Las practicas de la terapia de red (pp. 86-108). Barcelona: Gedisa. (Trabalho original publicado em 1987)

Rampage, C., \& Avis, J. M. (1998). Identidade sexual, feminismo e terapia familiar. Em M. Elkaïm (Org.), Panorama das terapias familiares, Vol 1 (E. C. Heller, Trad.) (pp. 189-221). São Paulo: Summus. (Trabalho original publicado em 1995)
Saffioti, H. I. B. (1997). No fio da navalha: violência contra crianças e adolescentes no Brasil atual. Em F. R. Madeira (Org.), Quem mandou nascer mulher? (pp. 135-213). Rio de Janeiro: Rosa dos Tempos.

Santos, B. S. (1999). Um discurso sobre as ciências (11 a ed.). Porto: Afrontamento.

Secretaria Nacional de Políticas sobre Drogas - SENAD () (2010). A prevenção do uso de drogas e a Terapia Comunitária. Retirado em 18/08/2010, de http://www.obid.senad.gov.br/portais/ OBID/conteudo/index.php?id_conteudo $=11198 \&$ rastro=PUBLICA $\% \mathrm{C} 3 \% 87 \% \mathrm{C} 3 \% 95 \mathrm{ES} /$ Cartilhas $\% 2 \mathrm{C}+$ livros+e+folhetos.

Sluzki, C. E. (1996). Violência familiar e violência política: implicações terapêuticas de um modelo geral. Em D. F. Schnitman (Org.), Novos paradigmas, cultura e subjetividade (J. H. Rodrigues, Trad.) (pp. 228-243). Porto Alegre: Artes Médicas. (Trabalho original publicado em 1994)

Speck, R. (1989). La intervención de red social: Las terapias de red, teoria y desarrollo. Em M. Elkaïm (Org.), Las practicas de la terapia de red (pp. 20-39). Barcelona: Gedisa. (Trabalho original publicado em 1987)

von Foerster, H. (1988). Construyendo una realidad. Em O. Watzlawick y otros (Orgs.), La realidad inventada. Como sabemos o que creemos saber? (pp. 38-56). Barcelona: Gedisa.

Watzlawick, P., Weakland, J. H., \& Fisch, R. (1977). Mudança: principios de formação e resolução de problemas (J. Martins, Trad.). São Paulo: Cultrix. (Trabalho original publicado em 1973)

White, M. (1997). Guias para una terapia familiar sistemica. Buenos Aires: Paidós. (Trabalho original publicado em 1989)

Wittzaele, J-J., \& Garcia, T. (1998). A abordagem clínica de Palo Alto. Em M. Elkaïm (Org.), Panorama das terapias familiares, Vol. 1 (E. C. Heller, Trad.) (pp. 180-224). São Paulo: Summus. (Trabalho original publicado em 1995)

Zimmerman, J., \& Dickerson, V. C. (1998). A técnica da narração no campo da psiquiatria e o trabalho de Michael White. Em M. Elkaïm (Org.), Panorama das terapias familiares, Vol. 2 (E. C. Heller, Trad.) (pp. 252-274). São Paulo: Summus. (Trabalho original publicado em 1995) 